\title{
Factors that Help Teachers to Create Successful Inclusive Classroom for Students with Learning Disabilities
}

\author{
Alanood Bin Jardan
}

Academic

\begin{abstract}
The purpose of the paper is to address the definition of including children with learning disabilities in general classroom in elementary schools. Identifying instructional techniques that teachers can implement to create successful inclusion classroom and the type of inclusive classrooms that encourages children with learning disabilities to succeed. The role of the teachers as well as parents is necessary in order to enhance children with learning disabilities in elementary schools to benefit from inclusion.
\end{abstract}

Keywords: Inclusion classroom, learning disabilities, factors, techniques, and instruction

\section{Introduction}

For the last few years, there has been emphasis on placing students with learning disabilities in inclusive classroom with their nondisabled peer. Inclusion by definition means to include someone into a place in which he/she has not previously been allowed. Inclusive classroom for students with learning disabilities means that they participate in classroom activities, are accepted by teachers and peers, and they can achieve their academic and social-emotional potential [Heward, 2013]. However, as a teacher in inclusive setting, this emphasis has become a quite challenging in many areas. Some of general education teachers are not trained or prepared for such setting. Also, they might not have much skills or strategies that assist them on teaching students with learning disabilities. Increasing the movement toward inclusive classroom leads to increase teachers' responsibilities and their roles as well. Therefore, it is necessary to determine and implement instructional techniques to ensure that inclusion is beneficial for students with learning disabilities.

\section{Purpose and Rationale for the Study}

The movement toward including students with learning disabilities leads to divide the professional in the field of special education into two groups. One group emphasize on educating students with learning disabilities in classroom with their nondisabled peers. They appeal that all students are equal, spite their disabilities, and they have equal opportunity to learn side by side with students without disabilities. Also, they believe that students with learning disabilities tend to learn effectively in inclusive classrooms because it provides appropriate instruction and support that benefits all students. Rea, McLaughlin \& Walther-Thomas [2002] stated that students with learning disabilities tend to have a better learning out come when they are placed in inclusive classrooms [as cited in Heward, 2013]. Further, when students with learning disabilities attend separate classroom, that negatively affect their self-esteem; as a result, advocacy group emphasize to inclusive classroom to increase social interacting of these students. Singh [2012] found that inclusive classroom leads to improve social skills and social interactions for students with learning disabilities. However, in order to create effective inclusive classrooms, teachers need a variety of methods or techniques to successfully benefits students with learning disabilities. There are many reason of conducting this study. First, to determine the most effective strategies, which teachers can apply in inclusion setting. Second, to identify the characteristics of successful inclusive classrooms. Also, to increases the emphasis on equal education for students with learning disabilities, and decrease the negative effects of labeling these students, as they are different because they are educated in separate setting.

\section{Constructs:}

In order to conduct this study, it is important to address a few constructs. First, the number student with learning disabilities has increased in the past few years. As a result, many professionals and educators emphasize on including these students in the general education classrooms. I chose to conduct this study on students with learning disabilities because I want to identify if inclusive classroom is the most appropriate setting for these students, and if they successfully achieve their academic goals while attending these classrooms. Also, since there has been increase to include students with learning disabilities in general education classroom, the necessity of determining the most effective instructional strategies increase as well. I chose this study because I seek for identifying and providing teaching techniques that can benefit these students in such educational setting.

\section{Research questions:}

The purpose of this study is to find answers for these two research questions: A) What are the main strategies that can help teaching in inclusive classrooms for students with learning disabilities in elementary school in Nashville? B) What are the benefits of inclusive classroom for students with learning disabilities in elementary school in Nashville?

\section{Literature Review}

One of the most difficult decisions that must be made once a student identified, as learning disabled is the concerns of the 


\section{International Journal of Science and Research (IJSR) \\ ISSN (Online): 2319-7064}

Index Copernicus Value (2015): 78.96 | Impact Factor (2015): 6.391

best type of educational placement to which he or she should be placed. For the past few decades, there has been a significant change regarding the appropriate placement for students with learning disabilities. A variety of regulations emphasize in including students with disabilities in regular education classrooms. In 1992, the National Association of Boards of Education [NASBE] wrote a report that emphasized for placing students with disabilities in regular education classroom, which gave birth to the inclusion movement [Bender, 2008]. Individual with Disabilities Education Act IDEA [2004] required that students with disabilities be included with their non-disabled peers, and they should have full entrance to the core curriculum to the maximum extent possible [Heward, 2013]. Further, the legislation of No Child Left Behind [2004] stated that students with disabilities must be included in general education classrooms with nondisabled peers [Olson, Platt, \& Dieker, 2008]. In addition, the movement toward inclusive placement is also supported by parents and educators who believe that students with learning disabilities have the right to be in the same classes as their non-disabled peers [Hitchcock, Meyer, Rose, \& Jackson, 2002].

Inclusion in the field of special education means that students with disabilities are included into general education classrooms with non-disabled students. Inclusive classrooms for students with learning disabilities indicate that these students are included in general classroom, which means that they participate in classroom activities, that they are accepted by teachers and peers, and that they achieve their academic and social-emotional learning [Heward, 2013].

Despite the legislations toward inclusion, professionals and educators in the field of special education are worried about placing students with learning disabilities in inclusion setting. Some of them believe that there are a variety of factors that must be considered before placing these students such as providing modification to curriculum by general education teacher to meet the needs of students with learning disabilities [Wagner, Newman, Cameto, Levine, \& Marder, 2003]. Moreover, other professionals are concerned about how inclusion being implement [Olson, Platt, \& Dieker, 2008]. According to Heward [2013] "some educators are concerned about inadequate instruction, teacher's limited understanding of learning needs of students with learning disabilities, and poor acceptance by teachers and peers" [p. 188]. However, many studies have shown that learning outcomes of students with learning disabilities increased in inclusive classrooms [Heward, 2013]. Students with learning disabilities tend to have higher peer acceptance and high number of friends when they are educated with their nondisabled peers [Winer \& Tardif, 2004]. In addition, Elbam [2002] stated that students with learning disabilities, who placed in regular education classrooms, show higher selfconcept than students who placed in other setting of special education classrooms [as cited in Heward, 2013]. Moreover, research has shown that inclusive education results in improving social development and academic achievement for all students with and without disabilities [Singh, 2012]. As the common practice in the educational system is the move toward inclusive classrooms, it is important that students with learning disabilities are classified. Individuals with Disabilities Education Act [IDEA] defined learning disabilities "as a disorder in one or more of the basic psychological processes involved in understanding or in using spoken or written language which may manifest itself in an imperfect ability to listen, think, speak, read, write, and spell or to do mathematical calculations" [as cited in Heward, 2013, p. 160].However, students with learning disabilities exhibit a discrepancy between intellectual ability and academic achievement which leads to difficulty in identifying and classifying a student as a learning disabled [Bender, 2008]. Also, in order for a learning disability to be determined various factors must be considered. These factors involve that these learning difficulty is not the primarily result of other health impairment, such as visual, hearing, or motor skills impairment, or other emotional or behavior deficits [Heward, 2013].

According to U.S Department of Education [2009] students with learning disabilities receive special education services as the largest category of all special education categories [as cited in Heward, 2013]. In addition, studies have demonstrated that the number of boys identify as learning disabled is more than the number of girls who determine as students with learning disabilities [Bender, 2008]. Furthermore, in spite of limited in academic achievement of students with learning disabilities, these students demonstrate lower attention, hyperactive or disruptive behaviors, lower self-concept, and difficulty interacting with peers [Bender, 2008]

In 2008-09, research has shown that all most $62 \%$ of students who have learning disabilities were educated in regular education classroom [Heward, 2013].This movement toward inclusion is critical in how educators in general classrooms view their responsibilities and their roles to the students who receive special education services. This inclusive approach of teaching students with learning disabilities in general classroom results to challenging teachers [Singh, 2012]. Casey, Williamson, Black, \& Casey, 2014 indicated that $52 \%$ of teachers who teach in inclusive classroom struggled in teaching students with learning disabilities. As a result, it is significantly important to create successful inclusion, which depends on implementing effective strategies and techniques that benefits all students. There is a discussion in the literature about instructional strategies that can be used in inclusive classrooms.

Several of studies have demonstrated a variety of strategies that teachers can implement in inclusive classrooms. Bender [2008] stated that teachers should apply differentiated instruction for inclusive class to meet the needs of students with learning disabilities. He emphasized on implementing cubing technique "as one instructional option for differentiating the instructional demands for students with learning disabilities" [p. 286]. Graham, Harris, and Larsen [2001] stressed that teachers should implement a variety of teaching methods, direct and indirect learning opportunities, and differentiation of instruction in educating students with learning disabilities in inclusive setting [as cited in Casey, Williamson, Black, \& Casey, 2014].

In addition, Olson, Platt, \& Dieker [2008] stressed that reciprocal teaching, which concentrates on teaching students how to gain meaning from reading text, as a strategy that 


\section{International Journal of Science and Research (IJSR) \\ ISSN (Online): 2319-7064}

Index Copernicus Value (2015): 78.96 | Impact Factor (2015): 6.391

assist students with learning disabilities to be successful in general education classrooms. Furthermore, Heward [2013] found that content enhancement approach is helpful for high school students who are learning disabled. This approach includes graphic organizers, visual displays, not-taking strategies, and mnemonics [Heward, 2013]. Research has shown that inclusive classroom can be effective if teachers use task analysis, adapt the curriculum, implement visual aids, emphasize phonemic awareness, and use assistive technology [Nowicki \& Brown, 2013]. In addition, Preus [2012] found that teachers in inclusive classrooms used strategies that encourage high thinking skills, such as, asking probing and constant questions, promoting metacognitive thinking, providing writing prompts that required analyzing and estimating, and giving effective feedback.

Since students with learning disabilities exhibit poor attention skills, it is important that teachers use several of techniques to ensure that learning-disabled students are engaged to the lesson. McGhie-Richmond, Underwood \& Jordan [2007] indicated " effective teaching practices that can benefit all students focus on high level of students engagement, together with excellent managerial and time management skills that teachers are able to provide to individual and groups during lessons" [p. 42]. Also, to provide effective instructional practice, teachers can implement reductionist paradigm, constructivist paradigm, and combining paradigm to ensure that learning-disabled students are engaged to the lesson [Olson, Platt, \& Dieker, 2008].Moreover, because students with learning disabilities demonstrate inadequate social skills, it is necessary that teachers provide some strategies to increase social skills for these students in inclusive classrooms. Singh [2012] found that peer tutoring and cooperative learning is strategies that used to increase students' achievement and social development as well. Preus [2012] found that grouping activities should be flexible, in which teachers site students in different groups depending on the specific needs of individual, as a technique to improve social skills and academic achievement for all students.

On the other hand, it is extremely important to provide students with learning disabilities with variety of selfinstructional strategies that help them succeed in general education classrooms. Bender [2008] determined the effectiveness of applying metacognitive model of instruction while teaching students with learning disabilities to assist their independence learning. In addition, Olson, Platt, \& Dieker [2008] stated "cognitive strategies provide students with a set of self-instructional steps that assist them in addressing a specific need" [p.197]. In addition, implementing self- regulated and self-monitoring improve students' ability to create their own strategies that help them increase their academic performance as well as behavioral development [Bender, 2008; Olson, Platt, \& Dieker, 2008].

Recently, the use of universal design for learning in inclusive classrooms has been increased in the field of education. This approach is defined as creating a lesson that is accessible to all students [Olson, Platt, \& Dieker, 2008]. The purpose of creating instruction that universally designed is to ensure success of all students despite their difficulties and their learning style. There are three principles to this approach. Olson, Platt, \& Dieker [2008] defined them as “ multiple means of representation, multiple means of expression, and multiple means of engagement" [p. 135]. When teachers apply universal design for learning in inclusive classrooms, students with learning disabilities as well as students without disabilities tend to increase their academic performance.

\section{Methods}

\section{Participants:}

Six elementary school teachers in Nashville teaching students with learning disabilities in inclusive classrooms are selected to take a part in this study. Three of them teach in public school while other three are teaching in private school. They teach classroom that includes 3 students with learning disabilities among 27 nondisabled students. They teach different subjects, such as reading, math, writing, and social study. To conduct this study, I will obtain ethics approval from school district here in Nashville. Then I will contact by e-mail and describe the study to the principals of the schools, where students with learning disabilities are educated in inclusive setting. Principals who express an interest in the study will allow me to visit the school and examine the setting in more detail. After attending many classrooms, I will select the best classrooms that I believe to be representative to my study. Then I will contact the teachers of these classrooms, and provide them with information about the study. Teachers who approve to be part of this study are selected as a participant to conduct the study.

\section{Data collection methods:}

Every participant are observed and interviewed separately. I will observe each teacher two times, and interview him or her two times as well. I will observe teachers during class instruction while I exploit one to one interviews in quiet rooms. On the observation, I will use videotapes to conduct the classroom's lesson, and I will start from the beginning of school day. I will inform the teachers that I come to observe students while they are teaching. No questions or concerns will be asked after the observation. However, during the interview phase, I will use digital recorder to tape the interview. I will began with asking participants to provide me with a definition of who are students with learning disabilities and what dose inclusion setting mean? Then I will ask them to describe some of the classes, such as reading, math, and writing that students with learning disabilities might have difficulty to establish. Next, I will ask teachers about the most effective instructional strategies that they find them helpful for these students. Also, I will provide some of the instructional techniques that historically found to be effective, such as peer tutoring, metacognitive model, and self-regulated then I will ask them to describe these strategies and whether they use them or not. Finally, I will ask them if they have any other perspective of including students with disabilities in general education classrooms. Each interview session typically will take 10-15 minutes to be completed. After the interview, I will transcribe responses of participants individually.

\section{Volume 6 Issue 7, July 2017 www.ijsr.net}




\section{International Journal of Science and Research (IJSR) \\ ISSN (Online): 2319-7064}

Index Copernicus Value (2015): 78.96 | Impact Factor (2015): 6.391

\section{Results / Discussion}

There are several strategies that research has indicated are effective when teaching students with learning disabilities in inclusive classrooms. However, the data that are collected from this study will provide me of the most strategies and techniques that teachers' evidence is helpful for students with learning disabilities. This data will indicate if these strategies have positive impact in these students' performance academically, behaviorally, and socially. The data will also provide me with the specific methods that teachers use in order to improve the performance for these students. Further, the data will indicate if teachers implemented one or more of the research-based instructional strategies while teaching these students in inclusive classrooms. Also, the data will provide me with teachers' documents that prove increases and progresses in these students' performance when they used these strategies in their classrooms. When teachers teach their students with learning disabilities in inclusion setting, do they significantly benefit from learning with their non-disabled peers? The data also will provide me if it is important for students with learning disabilities to be educated in general education classrooms. This data will indicate if general classrooms tend to be the beneficial placement for these students to overcome their difficulties.In order to organize data, I will use interpretative approach. I will start with reading the data collected from the study, and identify the similarity between the interview responses and observation notes. Then, I will isolate information that are collected from analyzing the data and divide them into seven categories. Each category has a specific strategies or techniques that teachers reported as helpful. After that I will list all comments that include any connection to any strategies under their matching category. By this method, I am able to store my data and start analyzing. I want to ensure that data collected are able to provide me with answers for my research questions.

\section{Conclusion}

Overall, although creating successful inclusion classroom for students with learning disabilities is challenging, it is passible. However, there are many factors that teachers should take them under considerations. These elements include strategies, techniques, and methods that approved helping students with learning disabilities to achieve their high academic potential in inclusive classrooms. Furthermore, these students benefits from the inclusive classroom in the area of social and emotional skills. The results indicate that when students with learning disabilities are included with their nondisabled peers, their social and emotional skills improved appropriately.

\section{Future Scope}

There are ethical considerations that might occur before, during, or after conducting this study. I have to be careful about these ethical considerations. Before conducting this study, some of the ethical issues that may rise are the issues of confidentiality. Although I must gain the confidentiality from my participants by providing consent forms before the study, I may have a lack of maintaining the issue of confidentiality and data collection from my participants. Also, other ethical issue that might occur before the study is that I may inform the participant teachers that I want to observe their students, whereas the truth is that I want to observe their teaching strategies. This is because I do not want teachers to try to improve their teaching strategies when they know that my purpose is to observe their instructional techniques. I want their practices be natural without any change while I am observing.

During conducting this study, the issue of confidentiality also might occur. In this phase, I have to remove any information that may lead to identify the participants. For example, I have to be careful about keeping the files that contain the name and address of schools or the name and address of the teachers in safety place. Furthermore, the issue of confidentiality might raise in different aspect. It is necessary that I replace the name of schools or teachers while conducting this study. Also, I have to delete any addresses from the file once they are no longer needed. In addition, other ethical issue that also might occur during the study is that I may select the interview questions that include a specific strategy because I prefer to use these techniques when teaching students with learning disabilities, or because I believe of the effectiveness of using these techniques when teaching these students.

Moreover, I may face ethical issues after conducting this study. For example, the issue of confidentiality that is related to the identification of the participants might occur when I want to interpret the interview transcripts that were used in this study. These are some of the ethical issues that may raise before, during, or after the study.

\section{Limitation of the Study}

There are several limitations that may occur in this study. First, because this study involves a small number of participants, the findings may not be generalized to different population. Also, since the participants of this study are selected based on my perspective, the findings may have some bias. Further, the study is conducted in elementary level, which makes it hard to generalize the findings of this study to other type of setting, such as middle or high school level. It seems that future research are needed to determine the most effective strategies that can help teachers to create successful inclusive classrooms of students with learning disabilities in middle and high school level. In addition, because this is a qualitative research, it is common that the study has lack of valid in the conclusion. My interpretation of collecting data may contain my own reflect and opinions which leads to make the findings of the study invalid. To overcome this issue, I have to ask other professionals to review my study to ensure validity. Moreover, other limitation that might rise in this study is the effect of participants' needs. While collecting the data, I may need to change or paraphrase the interview questions based on the ability of the participants, which may lead the participants to provide me with inappropriate answer. This might make the results of the study unreliable. To overcome this problem, I have to create a different structure for every individual questions that can fit all my participants. 


\section{References}

[1] Bender, W. N. (2008). Learning Disabilities: Characteristics, identification, and teaching strategies $6^{\text {th }}$ edition. Pearson

[2] education.

[3] Casey, L. B., Williamson, R. L., Black, T., \& Casey, C. (2014). Teaching writing expression in the inclusive high school

[4] classroom: strategies to assist students with disabilities. National forum of applied educational research journal, 27, 1-2.

[5] Heward, W. L. (2013). Exceptional Children an Introduction to Special Education ${ }_{-} 10^{\text {th }}$ edition. Boston: Pearson.

[6] Hitchcock, C., Meyer, A., Rose, D., \& Jackson, R. (2002).

[7] Technical brief: access, participation, and progress in general curriculum. National Center on Accessing the General Curriculum. Retrieved from http://aim.cast.org.

[8] McGhie-Richmond, D., Underwood, K., \& Jordan, A. (2007). Developing effective instructional strategies for teaching

[9] in inclusive classrooms. Exceptionality Education Canada, 17, 1, 27-75.

[10] Nowicki, E. A., \& Brown, J. D. (2013). "A Kid Way": Strategies for Including Classmateswith Learning and Intellectual

[11] Disabilities. Intellectual andDevelopmental Disabilities, $51,4$.

[12] Olson, J. L., Platt, J. C., \& Dieker, L. A. (2008). Teaching Children and Adolescents with Special Needs. $-5^{\text {th }}$

[13] edition. Pearson Education, Inc.Preus, B. (2012).

[14] Authentic instruction for $21^{\text {st }}$ century learning: higher thinking in an inclusive school. American Secondary Education, 40, 3.

[15] Singh, P. (2012). Teaching Strategies for Inclusive Classroom. International Journal of Education Research and Technology. 3, 2, 157-163.

[16] Wagner, M., Newman, L., Cameto, R., Levine, P., \& Marder, C. (2003). Going to school: instructional contexts, programs, and participation of secondary school students with disabilities. A report from the National Longitudinal Transition Study-2 (NLTS-2). Available:

http://www.nlts2.org/reports/2003_12/nlts2_report_200 3_12_complete.pdf.

[17] Wiener, J., \& Tardif, C. Y. (2004). Social and emotional functioning of children with learning disabilities: Does special education placement make a difference? Learning DisabilitiesResearch and Practice, 19, 20-32.

\section{Author Profile}

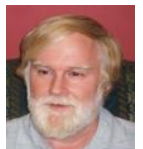

William Bender has 28 of experience as educator in high education. He wrote over 60 research articles and 24 books in the area of education. His areas of expertise include instructional strategies, differentiated instruction, project- based learning, and response to

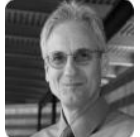

William L. Heward, Ed.D., BCBA-D, is professor emeritus in the College of Education and Human Ecology at The Ohio State University. His publications include more than 100 journal articles and book chapters and nine books. He has been a Senior Fulbright Scholar in Portugal, a visiting scholar at the National Institute of Education in Singapore, a visiting professor of Psychology at Keio University in Tokyo and at the University of São Paulo, Brazil, and has given lectures and workshops in 18 other countries.

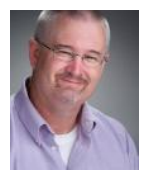

Robert L. Williamson, Ed.Dis a professor of Special Education at The University of Memphis. He has been supporting people with disabilities for over 20 years in several areas. He wrote many journals in many different subjects in the area of helping people with learning disabilities. intervention. 